\title{
Nested and swaddled positioning support in the prone position facilitates sleep and heart rate stability in very low birth weight infants
}

This article was published in the following Dove Press journal:

Research and Reports in Neonatology

4 April 2013

Number of times this article has been viewed

\author{
Hideki Kihara' \\ Tomohiko Nakamura² \\ 'Department of Rehabilitation, \\ Nagano Children's Hospital, \\ Nagano, Japan; ${ }^{2}$ Division of \\ Neonatology, Nagano Children's \\ Hospital, Nagano, Japan
}

Correspondence: Tomohiko Nakamura Division of Neonatology, Nagano Children's Hospital, 3100 Toyoshina, Azumino, Nagano, 399-8288, Japan Email tnakamura@naganoch.gr.jp

\begin{abstract}
The purpose of this study was to observe in very low birth weight infants (VLBWI) the effect of nested and swaddled positioning support in the prone position on heart rate, sleep distribution, and behavior state. A total of 20 VLBWI who were born at a gestational age of $26.5 \pm 4$ weeks with a birth weight of $709 \pm 207 \mathrm{~g}$ were studied at an average gestational age of $37.4 \pm 0.6$ weeks (range 36-39) and a weight of $1590 \pm 337 \mathrm{~g}$ (range 1192-2372). A prospective and crossover design was used. Infants were observed in the prone position with and without positioning support. Heart rate and electroencephalography were monitored during 3-hour interfeeding epochs. Heart rate and the coefficient of variation of heart rate in prone infants with positioning support were lower than in prone infants without positioning support. The percent of quiet sleep and behavior state 1 in prone infants with positioning support were higher compared to prone infants without positioning support. In conclusion, the present study demonstrated that a prone position with nested and swaddled positioning support might facilitate sleep and heart rate stability compared to prone positioning alone in VLBWI.
\end{abstract}

Keywords: positioning support, prone position, sleep, heart rate, very low birth weight infants

\section{Introduction}

Most of the literature regards the prone position as the position of choice in the neonatal intensive care unit. Preterm infants in the prone position display fewer stress responses such as startles, tremors, and twitches. ${ }^{1}$ Another physiologic benefit includes increased thoracoabdominal synchrony and rib cage motion. Pressure from the infant's weight against the supporting surface is believed to enhance the stability of the chest wall, allow for greater excursion of the diaphragm, and ultimately result in a mechanical advantage for breathing. ${ }^{2-4}$ In the prone position, positioning support is usually placed underneath the major weightbearing area to lift an infant's body off the supporting surface. Trunk and pelvic supports free the extremities from the effects of gravity, and thereby facilitate the infant's ability to adopt a physiologic tuck posture, simulating the intrauterine posture. ${ }^{5,6}$ There are some reports suggesting that use of the prone position with preterm infants can increase time in quiet sleep (QS) and decrease time spent crying or in active sleep (AS); ${ }^{1,7}$ in addition, it can decrease the amount of time spent awake with no significant difference in time spent in AS. However, the benefit of positioning support on central nervous system maturation is still under investigation. We hypothesize that positioning support may affect autonomic stability more than prone positioning alone. The purpose of this study is to observe the effect of positioning support in the prone position on the heart rate (HR), distribution of sleep, and behavior state in very low birth weight infants (VLBWI). 


\section{Subjects and methods Study population}

The present study included 20 VLBWI (13 males and seven females) who were born with a mean gestational age of $26.5 \pm 4$ weeks (range 22.7-32.5) and with a mean birth weight of $709 \pm 207 \mathrm{~g}$ (range 441-1420). The gestational age and weight when the infants were studied were $37.4 \pm 0.6$ weeks (range 36-39) and $1590 \pm 337 \mathrm{~g}$ (range 1192-2372), respectively. At this gestational age, premature infants show mature electroencephalography (EEG), which is similar to that of near-term infants. All patients were stable with no apnea or bradycardia and had full tube feeding. This study was based on informed consent from the parents and was approved by the Ethics Committee of the Nagano Children's Hospital.

\section{Experimental design}

A prospective, crossover design was used. Infants were studied both in the prone position using nested and swaddled positioning support and in the prone position without support. HR and EEG were monitored during 3-hour interfeeding epochs. First, the infants were placed in the prone position without any support for 1 hour. Then, the babies held the hand towel and were nested and swaddled with a special mat (Baby Positioning Mat, Akatyan No Shiro Corporation, Kurume, Japan) to keep the elbow, shoulder, hip, and knee joint in flexion for 1 hour (Figure 1), and then the infants were taken off the special mat in the prone position. The second study was performed at the same interfeeding epoch on the next day. Following evaluation in the prone position with a special mat for 1 hour, infants were then taken off the special mat in the prone position for 1 hour, and were subsequently nested and swaddled with a special mat for 1 hour.

HR data was recorded by a body living information control system (Clinical Network System CAN-1100; Nihon Kohden Corporation, Tokyo, Japan). A HR of less than 50/bpm and greater than $200 / \mathrm{bpm}$ was considered
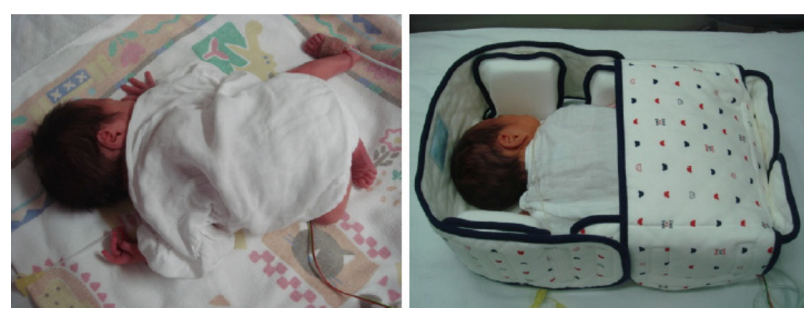

Figure I Prone infants without support (left) and with support using the new nested, swaddled mat. noise and were thus excluded. EEG data was recorded from an electroencephalograph (Neurofax EEG-1714; Nihon Kohden Corporation, Tokyo, Japan) with the eight-channel method. Sleep data from the EEG were evaluated as QS (high voltage, slow wave pattern, and trace alternant) or as AS (low voltage irregularity pattern and wave mixing).

Data was collected every minute. The states were evaluated using Brazelton and Nugent's index; ${ }^{8}$ state 1 was deep sleep with eye closure, no eye movements, regular breathing, and no spontaneous movement; state 2 was light sleep with eye closure, eye movements, irregular breathing, and slight spontaneous movement; state 3 was slumber with eyes opened or closed ("heavy eyes"), eye movements, irregular breathing, and sporadic spontaneous movement; state 4 was arousal with eyes open ("eyes with alacrity"), and slight spontaneous movement; state 5 was excitement with brief periods of being cranky and active spontaneous movement; and state 6 was crying with violent intense crying and active spontaneous movement. The infant's state was classified every minute in real time. The state was reassessed by video recording if the state was unclear.

\section{Results}

Figures 2 and 3 show the HR and the coefficient variation of HR (mean \pm standard deviation). HR in prone infants with positioning support $(153.7 \pm 15.9 / \mathrm{bpm})$ was lower than without positioning support (157.7 $\pm 17.1 / \mathrm{bpm})$. The coefficient of variation of HR in prone infants with positioning support $(0.057 \pm 0.02 / \mathrm{bpm})$ was also lower than without positioning support $(0.078 \pm 0.023 / \mathrm{bpm})$.

Figure 4 shows the percent of QS and AS in prone infants with and without positioning support. The percent of QS in prone infants with positioning support (24\%) was high compared to those without positioning support (7\%). The percent of AS was almost the same among prone infants

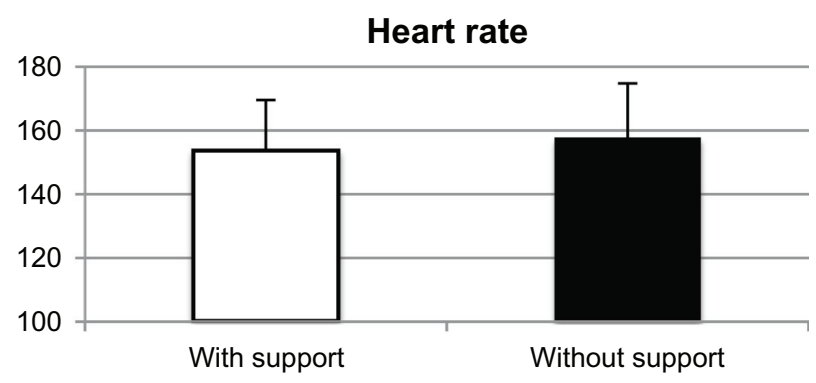

Figure 2 Heart rate (beats per minute) in prone infants with positioning support (left) and without positioning support (right) (mean \pm standard deviation). 


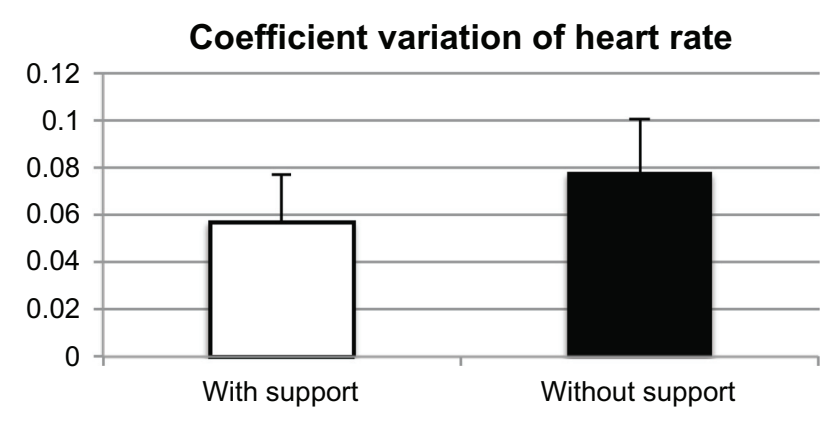

Figure 3 Coefficient variation of heart rate in prone infants with positioning support (left) and without positioning support (right) (mean \pm standard deviation).

with positioning support (70\%) and without positioning support $(66 \%)$.

Figure 5 shows the percent of each state in prone infants with and without positioning support. The percent of state 1 in prone infants with positioning support (27\%) was high compared to prone infants without positioning support (6\%). The percent of state 2 was almost the same as in prone infants with positioning support $(65 \%)$ and without positioning support (63\%). The percent of other sleep states in prone infants without positioning support (state 3, 19\%; state $4,1 \%$; state $5,7 \%$; and state $6,5 \%$ ) were high compared to prone infants with positioning support (state 3, 9\%; state $4,0 \%$; state $5,0 \%$; and state $6,0 \%$ ).

\section{Percent of sleep in infants with positioning support}

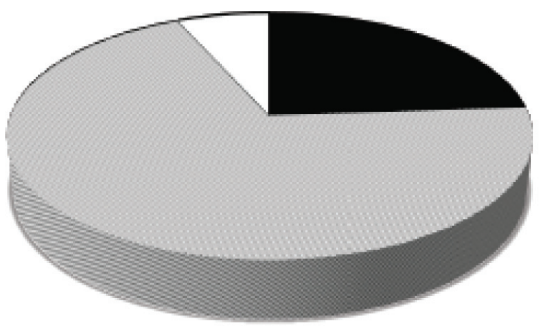

Quiet sleep

V Active sleep

$\square$ Others

\section{Percent of sleep in infants without positioning support}

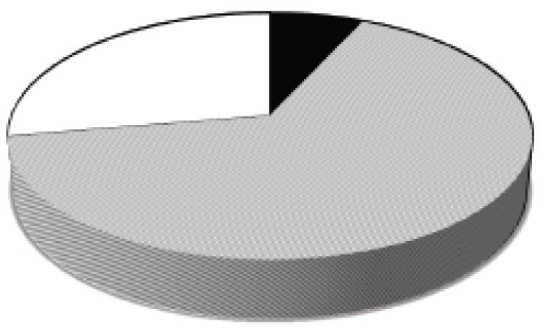

Quiet sleep

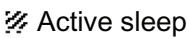

$\square$ Others

Figure 4 Percent of sleep state in prone infants with positioning support and without positioning support.

\section{Percent of state in infants with positioning support}

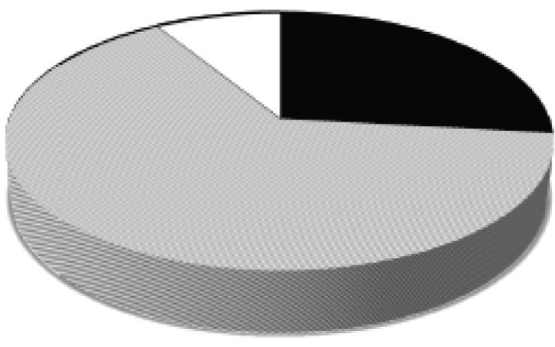

State 1

\% State 2

State 3

State 4

$\equiv$ State 5

State 6

\section{Percent of state in infants without positioning support}

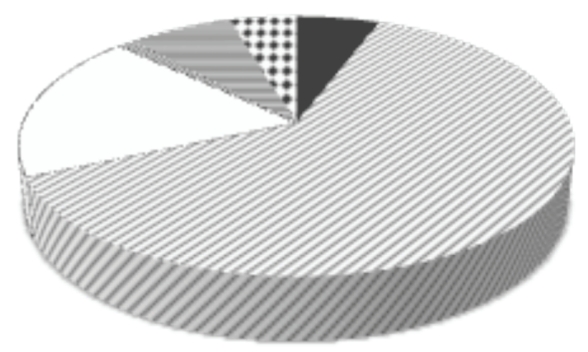

State 1

$/$ State 2

$\square$ State 3

NState 4

$\equiv$ State 5

- State 6

Figure 5 Percent of sleep state in prone infants with positioning support and without positioning support.

\section{Discussion}

The different sensorimotor experience of premature infants compared with infants born at term may interfere with their sensorimotor development. The fetus in utero has spent most of his or her time in QS and was able to keep a stable HR to save energy; however, premature infants experienced different sensorimotor stressors, such as sound, light, and pain.

Several studies have reported that the prone position in preterm infants increases their time in QS. ${ }^{1,9-11}$ The mechanism behind how sleeping position influences sleep organization is still unclear. Harper ${ }^{12}$ has suggested that sleep state after a period of feeding is different from after a nonfeeding period of prolonged wakefulness. It is known that the ingestion of food increases the metabolic rate. This change in metabolic rate could influence the temporal pattern of sleep during interfeed periods. Less energy expenditure and a reduced ability to lose heat have been reported in prone-sleeping infants. ${ }^{10}$

Premature infants have higher parasympathetic nerve activity compared with term infants..$^{13}$ There are intense relationships between HR variability and sympathetic, as well as parasympathetic nerve activity. The results of this study demonstrate that in very low birth infants, positioning 
support in the prone position enhances HR stability and leads to relaxation. We assumed that positioning support in the prone position, by providing the infant with period of relaxation, would lead to less energy expenditure and thereby enhance growth and brain development. So far, there is no report linking sleep state disturbances with later learning or neurodevelopmental outcomes. Further observations using this new positioning mat may demonstrate improved later learning or neurodevelopmental outcomes in VLBWI. In conclusion, the present study showed that this new nested and swaddled prone positioning supports facilitated sleep and HR stability compared to prone positioning alone in VLBWI.

\section{Acknowledgments}

This study was funded by a grant for scientific research by the Ministry of Health and Welfare of Japan.

\section{Disclosure}

The authors report no conflicts of interest in this work.

\section{References}

1. Chang Y, Anderson GC, Lin CH. Effects of prone and supine positioning on sleep state and stress responses in mechanically ventilated preterm infants during the first postnatal week. $J$ Adv Nurs. 2002;40(2): $161-169$.

2. Fox RE, Viscardi RM, Taciak VL, Niknafs H, Cinoman MI. Effect of position on pulmonary mechanics in healthy preterm newborn infants. J Perinatol. 1993;13(3):205-211.
3. Martin RJ, DiFiore JM, Korenke CB, Randal H, Miller MJ, Brooks LJ. Vulnerability of respiratory control in healthy preterm infants placed supine. J Pediatr. 1995;127(4):609-614.

4. Wolfson MR, Greenspan JS, Deoras KS, Allen JL, Shaffer TH. Effect of position on the mechanical interaction between the rib cage and abdomen in preterm infants. J Appl Physiol. 1992;72(3):1032-1038.

5. Downs JA, Edwards AD, McCormick DC, Roth SC, Stewart AL. Effect of intervention on development of hip posture in very preterm babies. Arch Dis Child. 1991;66(7 Sec No):797-801.

6. Monterosso L, Coenen A, Percival P, Evans S. Effect of a postural support nappy on 'flattened posture' of the lower extremities in very preterm infants. J Paediatr Child Health. 1995;31(4):350-354.

7. Kurlak LO, Ruggins NR, Stephenson TJ. Effect of nursing position on incidence, type, and duration of clinically significant apnoea in preterm infants. Arch Dis Child Fetal Neonatal Ed. 1994;71(1):F16-F19.

8. Brazelton TB, Nugent JK. The standard administration of the NBAS. In: Neonatal Behavioral Assessment Scale, 3rd ed. London, UK: Cambridge University Press; 1995:7-40.

9. Sahni R, Saluja D, Schulze KF, et al. Quality of diet, body position, and time after feeding influence behavioral states in low birth weight infants. Pediatr Res. 2002;52(3):399-404.

10. Goto K, Mirmiran M, Adams MM, et al. More awakenings and heart rate variability during supine sleep in preterm infants. Pediatrics. 1999; 103(3):603-609.

11. Myers MM, Fifer WP, Schaeffer L, et al. Effects of sleeping position and time after feeding on the organization of sleep/wake states in prematurely born infants. Sleep. 1998;21(4):343-349.

12. Harper RM. The cerebral regulation of cardiovascular and respiratory functions. Semin Pediatr Neurol. 1996;3(1):13-22.

13. Akselrod S, Gordon D, Ubel FA, Shannon DC, Berger DC, Cohen RJ. Power spectrum analysis of heart rate fluctuation: a quantitative probe of beat-to-beat cardiovascular control. Science. 1981;213(4504): $220-222$.

\section{Publish your work in this journal}

Research and Reports in Neonatology is an international, peer-reviewed, open access journal publishing original research, reports, editorials, reviews and commentaries on neonatal health. The manuscript management system is completely online and includes a very quick and fair peer-review system. Visit http://www.dovepress.com/testimonials.php to read real quotes from published authors. 